\title{
INDAGAÇÕES SOBRE AS NOVAS FORMAS \\ DE FABRICAÇÃO DO HUMANO Ȧ LUZ DA NOÇÃO DE DÁDIVA DE MARCEL MAUSS
}

Simone Perelson e Isabel Fortes

Universidade Federal da Fronteira Sul, Chapecó, SC, Brasil

Simone Perelson

Professora adjunta

da Escola de

Comunicação e

do Programa de

Pós-graduação

em Teoria

Psicanalítica da UFRJ.

Isabel Fortes

Professora

assistente da

graduação e da

pós-graduação

do Departamento

de Psicologia da

PUC-Rio; bolsista

de produtividade

em pesquisa do

CNPq.
RESUMO: Buscaremos articular a lógica implicada nas doações de material de engendramento (sêmen, óvulos e embriões), praticadas no campo das novas tecnologias reprodutivas (NTR), com o sistema de trocas de algumas sociedades arcaicas, descrito por Marcel Mauss em seu célebre artigo Ensaio sobre a dádiva (1924/1974). Esta articulação será também trabalhada a partir de três importantes intérpretes deste ensaio — Lévi-Strauss, Maurice Godelier e George Bataille —, de modo a extrair dela algumas consequências e explicitar alguns questionamentos que as NTR colocam para a psicanálise e vice-versa. Palavras-chave: Novas tecnologias reprodutivas, sistema de trocas, dádiva, excesso.

ABSTRACT: Questioning the new forms of human fabrication in the light of Marcel Mauss's concept of gift. In this article, we will articulate the logic involved in donations from engenderment material (semen, eggs and embryos), practiced in the field of new reproductive technologies, with the system of exchanges of some archaic societies described by Marcel Mauss in his celebrated article Essay on the gift (1924/1974). This articulation will also be crafted from three important interpreters of this essay - Lévi-Strauss, Maurice Godelier and George Bataille - in order to extract some consequences and clarify some questions that the NRT address to psychoanalysis and vice versa

Keywords: New reproductive technologies, exchange system, gift, excess.

DOI - http://dx.doi.org/10.1590/S1516-14982015000100006 


\section{INTRODUÇÃO}

A partir de meados do século passado, com o desenvolvimento e a prática das chamadas novas tecnologias reprodutivas (NTR), uma nova forma de fabricação de crianças e, consequentemente, famílias começou a ganhar lugar. Hoje, este desenvolvimento já se acha bastante avançado e esta prática já se tornou tão difundida quanto familiar. A antropologia tem se debruçado bastante nos últimos anos sobre os elementos colocados em cena por essas tecnologias.

A psicanálise tem se mostrado, a esse respeito, muito mais tímida. Uma fundamental contribuição neste árido campo é a articulação sugerida pela psicanalista Geneviève Delaisi de Parseval entre a lógica implicada nos dons de material de engendramento — sêmen, óvulos e embriões — e aquela que Marcel Mauss descreve a respeito das formas de troca que ele encontra nas sociedades arcaicas em seu célebre Ensaio sobre a dádiva (1924/1974). Pretendemos neste artigo explorar a articulação sugerida pela psicanalista a partir tanto das formulações de Mauss sobre a dádiva (don) quanto de três importantes intérpretes de seu ensaio - Lévi-Strauss, Maurice Godelier e George Bataille — , de modo a extrair desta articulação algumas consequências e explicitar, a partir dela, algumas interrogações que as NTR colocam para a psicanálise e vice-versa.

Antes de avançarmos, é necessário, entretanto, observar que neste primeiro parágrafo já se insinua uma série de questões que exigiriam, cada uma delas, um amplo esclarecimento.

Em primeiro lugar: o que são as chamadas NTR e em que medida se pode afirmar sua novidade com relação às práticas reprodutivas anteriores? Dada a amplitude dessa questão, não será possível aqui tratá-la a contento. Para o nosso objetivo, basta referirmos as chamadas novas tecnologias reprodutivas às práticas de reprodução em que um ato técnico substitui o ato sexual na origem da vida (inseminações artificiais e fertilizações in vitro) e em que o material de seu engendramento (óvulos, sêmen ou embrião) é disponibilizado (manipulado, estocado, congelado, descartado, doado ou comercializado) fora do corpo (considerado até há pouco seu receptáculo natural).

Em segundo lugar, cabe esclarecer que, visto as taxas de sucesso dos mais sofisticados tratamentos alcançarem ainda hoje no máximo $40 \%$ de chances, o avanço das NTR a que nos referimos diz respeito menos ao resultado e à eficácia dos tratamentos do que à diversificação e complexificação de suas técnicas.

Em terceiro lugar, cabe destacar que se, por um lado, ao formularmos que as NTR se tornaram hoje familiares, buscamos destacar o duplo sentido do termo (comum ou banal e, ao mesmo tempo, forma de constituição de famílias), por outro, o recurso ao termo comporta um grave risco: eclipsar seu caráter estranho (unheimlich), o fato de, nessas práticas, o familiar aparecer sob a forma do novo e o novo aparecer sob uma forma familiar. Afirmar que se tornaram familiares, 
portanto, não significa negar que as novas práticas reprodutivas e familiares causem estranhamentos, desconcerto e assombro.

Feitas estas três observações, é possível agora adentrarmos nosso campo investigativo.

As novas práticas de reprodução (e filiação) incluem, como já dito, a disponibilização, fora do corpo, do material de engendramento. Este, por sua vez, torna-se passível, entre outros destinos, de circulação: comercialização (autorizada apenas em pouquíssimos países, entre os quais os Estados Unidos) ou doação. É precisamente a circulação deste material, a qual se encontra hoje cada vez mais na origem tanto da fabricação de crianças (e filhos) quanto da produção de laços sociais (entre doadores, receptores e seres gerados a partir das doações) que nos parece exigir uma séria reflexão. Como compreender essa estranha circulação de um também estranho material, cada vez mais presente na constituição das novas famílias e sociedades?

Os dispositivos médico e jurídico apressaram-se, em todos os países onde a circulação de material de engendramento foi colocada em cena, em impor normas que pudessem reger a contento esta circulação. Embora haja grande diversidade normativa entre os diferentes países e já seja possível observar nos últimos anos importantes modificações em suas normas, estas se reduzem basicamente a cinco elementos: a gratuidade, o anonimato, o sigilo médico, a semelhança fenotípica e os princípios de seleção para doadores e receptores. As duas primeiras normas buscam, respectivamente, sustentar as ideias de que o fundamento da circulação é o altruísmo e que ela não dá lugar a nenhuma forma de laço de parentesco entre os adultos (receptores e doadores), nem tampouco entre estes últimos e os frutos da doação (as crianças). Talvez pelos riscos que permanecem latentes, insistindo em anunciar que as coisas talvez não se passem dessa forma, as três últimas normas podem ser úteis caso se torne necessário recusar seja o retorno do recalcado, seja a realidade desmentida, seja o real foracluído: a presença de alguma forma de laço (mesmo que este não se confunda com o do parentesco nos moldes que o compreendemos hoje) e de outros afetos que não apenas o altruísmo.

Evidentemente, as normas médicas e jurídicas (no Brasil, muito mais médicas do que jurídicas) não homogeneízam os sentidos (conscientes e inconscientes) nem as ausências de sentido que o sistema de trocas do material de engendramento impõe aos sujeitos singulares que dela fazem parte. Não é nossa intenção abordá-las aqui, o que só poderia ser feito no caso a caso e não admitiria generalizações. O que pretendemos, e aqui precisamos melhor o objeto e objetivo do artigo, é buscar algumas ferramentas teóricas que nos permitam trazer, mesmo que parcialmente, à luz (ou meia-luz) o caráter estranho (unheimliche) desta nova forma de circulação que se encontra hoje no fundamento de laços familiares e 
sociais, caráter tão inquietantemente presente quanto claramente negado sob as formas do recalque, da denegação ou da foraclusão.

A abordagem do caráter ao mesmo tempo fundante e estranho da circulação de material de engendramento próprio às NTR será aqui introduzida por meio da importante leitura empreendida por Lévi-Strauss do Ensaio sobre a dádiva (1924/1974) de Mauss. Em seguida, exploraremos a articulação proposta por Geneviève Delaisi de Parseval (1994) entre a lógica que rege a dádiva e a lógica que, a seu ver, deveria reger os dons de gametas e embriões. Depois disso, apresentaremos a distinção proposta por Godelier entre três modalidades de objetos - aqueles que se vende (as mercadorias), aqueles que se dá (os objetos de dom e contra-dom), e aqueles que não são nem vendidos nem dados, mas guardados para serem transmitidos (as coisas sagradas). Enfim, abordaremos três modalidades de troca distinguidas por Maurice Godelier - a troca de mulheres, o kula e o potlach — esta última em especial suscitará o interesse de Bataille, filósofo que conduzirá à formulação das interrogações e formulações que concluirão este artigo.

\section{MAUSS E LÉVI-STRAUSS: A DÁDIVA E A LÓGICA ESTRUTURAL DA TROCA DE MULHERES}

Na introdução de Ensaio sobre a dádiva (1924/1974), Marcel Mauss expõe em poucas palavras o seu programa: a descrição das trocas que se fazem, em várias civilizações que nos cercam ou que imediatamente nos precederam, sob a forma de presentes, em teoria voluntários e gratuitos, mas que se revelam, na verdade, interessados ou, mais precisamente, obrigatoriamente dados e retribuídos. Não seriam apenas coisas úteis economicamente que são trocadas mas, antes de tudo, "gentilezas, banquetes, ritos, serviços militares, mulheres, crianças, danças, festas, feiras” (p.45). Enfim, surpreende ainda ao antropólogo o fato de grande parte dessas trocas serem marcadas pelo princípio da rivalidade e do antagonismo, de modo que o objetivo na doação dos presentes é em grande medida desafiar o donatário (o chefe da tribo rival), colocando-o na situação de impossibilidade de retribuir à altura o presente.

O tipo de troca que leva essa lógica ao extremo é o potlatch. Retornaremos a essa modalidade particular de troca mais adiante. Por ora, cabe apenas ainda destacar que, segundo Mauss, a moral e a economia dessa "forma necessária da troca” (p.42), que nos faz supor que existe na coisa dada uma força que faz com que o donatário seja forçado a retribuí-la e da qual "o mercado é apenas um dos momentos" (p.45), "funcionam ainda em nossas sociedades de maneira constante e, por assim dizer, subjacente” (p.42). Por essa razão, o antropólogo acredita ter nela encontrado "uma das rochas humanas sobre as quais são construídas nossas sociedades" (p.42). 
Estas formulações serão fundamentais para levar Lévi-Strauss, em sua "Introdução ao pensamento de Marcel Mauss” (1924/1974), a destacar que pela primeira vez na história do pensamento etnológico, o social torna-se um sistema. Ou seja, ele revela que os acontecimentos aparentemente fortuitos da vida social (como o nascimento, o casamento e a morte) podem ser reduzidos a um número limitado de combinações lógicas entre um número também limitado de elementos simbólicos determinados. O atento leitor de Mauss pode assim formular sua própria concepção: "toda cultura pode ser considerada como um conjunto de sistemas simbólicos, em cuja linha de frente situam-se a linguagem, as regras matrimoniais, as relações econômicas, a arte, a ciência, a religião" (idem, p.9).

Mas não é em qualquer sistema simbólico que Mauss encontrará o fundamento das sociedades, e sim naquele próprio ao que ele chamará de dádiva (don), ato que implica uma tripla necessidade — dar, receber, retribuir —, que cria dívidas e instala uma dupla relação entre doador e donatário de proximidade e distanciamento (GODELIER, 2007, p.70).

A partir da influência de Mauss, define-se um dos principais projetos de Lévi-Strauss: esclarecer a lógica dos diversos dons e contradons de mulheres presentes em diferentes sociedades, indicando ao mesmo tempo suas diferenças e seu ponto comum, assim como apontando o fato de que é sempre uma atualização particular de uma estrutura geral de troca de mulheres que se encontra no lugar de fundamento do social. Assim, por mais diferentes que sejam as inúmeras sociedades - arcaicas ou modernas - elas resultam sempre de diferentes, porém limitadas, combinações lógicas de determinados elementos simbólicos que constituem uma mesma estrutura. Concluindo: as trocas de mulheres se encontram no fundamento de toda sociedade sendo que diferentes, porém limitadas, formas de trocas de mulheres se encontram no fundamento de diferentes sociedades localizadas em diversos tempo e espaço.

Por mais diferentes, portanto, que possam parecer entre si as milhares de sociedades humanas, elas não deixam de estar referidas a uma estrutura lógica comum. É por isso que a interpretação estruturalista é, segundo o antropólogo, "uma operação do mesmo tipo que na psicanálise faculta-nos a reconquista, para nós mesmos, do nosso eu mais estranho e, na indagação etnológica, nos faz alcançar o mais estranho dos outros como se fosse um outro nós" (LÉVI-STRAUSS, 1924/1974, p.19).

A leitura que Lévi-Strauss empreende de Mauss nos serve como importante porta de entrada, em primeiro lugar, para a sustentação da ideia que os dons que circulam hoje nas NTR não têm apenas como consequência a possibilidade de que pessoas ou casais inférteis consigam ter filhos. Suas consequências e seu sentido podem ter um alcance muito mais profundo: eles podem, de fato, dizer respeito a importantes mutações no que diz respeito aos fundamentos da sociabilidade 
contemporânea, isto é, a lógica que rege os laços sociais que se encontram em sua base. Em segundo lugar, sua leitura indica que a interpretação estruturalista favorece o reconhecimento do caráter estranho (unheimlich) das lógicas particulares de troca próprias a cada sociedade. Aqui, o autor não poderia ser mais freudiano: o estranho é o mesmo sob a forma da alteridade ou a alteridade sob a forma do mesmo. Assim, pensar o estranho próprio à circulação de material de engendramento nas NTR implica articular essa circulação a outras formas de circulação que se deram ou se dão em outras sociedades ou em nossa própria sociedade de modo a revelar como o conhecido aparece, hoje, sob novas formas e como o novo aparece sob uma velha forma. Significa perceber que o que nos desnorteia nas NTR não é seu caráter absolutamente novo e desconhecido, mas, antes, a relação que elas colocam em cena entre o tradicional e o novo, entre o conhecido e o desconhecido.

De fato, como já indicamos acima, o dispositivo médico e jurídico busca transformar as novas formas de reprodução e filiação numa cópia ao mesmo tempo da velha conhecida "reprodução natural" (constituindo-se como um simulacro da mesma), e em alguns países, como, por exemplo, a França, da tradicional família monogâmica heterossexual. Eis a primeira forma de o estranho aparecer. Por outro lado, como já vimos aqui, Mauss, ao enumerar as coisas intercambiadas nas trocas sobre as quais são construídas nossas sociedades, cita as crianças e as mulheres. Sabemos que a circulação de crianças sempre se deu e continua se dando em todas as sociedades segundo lógicas próprias a cada uma delas. Quanto às mulheres, vimos que Lévi-Strauss as alça à categoria do mais precioso objeto das trocas que se encontram na origem da sociedade, a explicitação da estrutura que regula as suas trocas sendo, portanto, fundamental para compreendê-la.

Hoje, entretanto, um novo objeto de trocas - o material biológico de engendramento - e uma nova lógica — ou, antes, novas lógicas — parecem se impor no lugar da circulação de crianças e mulheres, emergindo na base de novas formas de laço social.

Qual relação podemos estabelecer entre estas três formas de circulação? É possível pensarmos em termos de um deslocamento (ou uma troca) dos objetos preciosos de troca que se encontram no fundamento de nossa sociedade: não mais crianças ou mulheres, mas gametas e embriões?

É possível pensar que a lógica que Lévi-Strauss revelou estar presente na troca de mulheres aparece atualizada de uma nova forma, na circulação de material de engendramento?

É possível vermos, então, nesta última a presença de uma lógica já conhecida sob uma forma desconhecida?

Antes de buscar responder a estas indagações, conferindo sentido ao eventual deslocamento em questão, por ora nos interessa, sobretudo, sustentar sua entra- 
da em cena, apontando que não são poucos os limites colocados à formulação de um sentido ou resposta para este possível deslocamento e estas necessárias indagações. Com efeito, a formulação destas questões refere-se ao nosso esforço não de explicar, mas de ao menos contornar o caráter estranho da circulação de material de engendramento. E para isso a articulação sugerida por Geneviève Delaisi de Parseval entre a dádiva e a circulação do material de engendramento nas NTR será de inestimável valia.

\section{MAUSS E GENEVIĖVE DELAISI DE PARSEVAL:}

\section{A DÁDIVA E OS DONS DE MATERIAL DE ENGENDRAMENTO}

Geneviève Delaisi de Parseval é uma psicanalista que vem se dedicando há vários anos à pesquisa em torno da parentalidade e das novas tecnologias reprodutivas e colaborado em inúmeros comitês de bioética. É bastante veemente em suas críticas à lógica médica e jurídica francesa que rege os dons de material de engendramento, e propõe, em seu lugar, o que chama de uma ética relacional (1994). A formulação desta ética se fundamentará, em grande medida, em sua reflexão sobre o sentido da dádiva revelado por Mauss

É, de fato, sustentada em sua leitura de Mauss que a psicanalista observa, em primeiro lugar, que todo gesto de doação de gametas — e, podemos acrescentar, de embriões - "se inscreve, como qualquer dom, em uma lógica de troca e de contradom" (DELAISI DE PARSEVAL \& VERDIER, 1994, p.148), de modo que "as instituições médicas devem favorecer a expressão desses contradons" (idem, p.153). É como o favorecimento dessa expressão que será entendida e sustentada pela psicanalista a ética relacional, a qual implica, evidentemente, uma colocação em causa da ideia norteadora da lógica que rege o dispositivo das doações de material de engendramento: o dom desinteressado e altruísta. Como observa Geneviève Delaisi de Parseval, citando um trecho do prefácio à edição inglesa do Ensaio sobre a dádiva de Mauss:

“O dom pretensamente desinteressado é uma ficção que concede excessiva importância à intenção daquele que dá (...). Ao recusar qualquer possibilidade de reciprocidade, cortamos o fato de dar de seu contexto social e o privamos de toda a sua significação relacional. Mas ninguém é enganado por essas petições de princípio e ao vermos os efeitos perversos induzidos pela afetação de generosidade desinteressada, seria melhor que o dom gratuito não tivesse jamais existido." (DELAISI DE PARSEVAL \& VERDIER, 1994, p.156-57)

Em segundo lugar, sustenta a autora, é necessário se compreender que o que se doa, sob a aparência de simples substâncias biológicas, “é a vida” (idem, p.148). 
Doa-se também “fantasmas que servirão para alimentar o romance familiar das crianças que vão nascer graças aos doadores” (ibidem). Doa-se, enfim, fils termo que, em francês tem o duplo sentido de filhos e laços. Revela-se aqui não apenas que o que se doa não é da ordem das coisas economicamente úteis, mas também que a doação em questão produz laços sociais.

Em terceiro lugar, sustentada na etimologia, na etnologia e na própria psicanálise, Parseval sublinha o aspecto ambivalente do presente (Gift) dado. Note-se que em alemão clássico, o termo tem um duplo sentido: presente e veneno. A etnologia, por sua vez, mostra que todas as partes e substâncias destacáveis (dejetos) do corpo (sêmen, sangue, leite, cabelos, etc.) são, em todas as sociedades tradicionais, percebidas como ligadas à magia, com toda a ambivalência que esta comporta. São, além disso, objetos considerados impuros. E, tanto do ponto de vista cultural quanto fantasmático, a impureza se liga à zona anal.

É, Freud, por sua vez, quem, revelando a cadeia inconsciente de equivalências simbólicas (excrementos — presente — criança — dinheiro) permitirá à psicanalista conferir um sentido metapsicológico (incluindo-se aqui o sentido econômico) ao material de engendramento (no caso, mais particularmente, ao sêmen), a esses dejetos do corpo, que, antes de serem doados, são estocados em instituições ou bancos que "os tratam, conservam, transformam em palhetas, enfim, agem à maneira dos banqueiros em seu trato com o dinheiro” (ibidem). Além disso, são laços secretos que são doados. Ou seja, o segredo funciona como um saber que é vivido pelos protagonistas sob o modo anal da retenção e do domínio. Para completar os elementos que atualizam a cadeia simbólica, a psicanalista ainda nos remete para o parentesco etimológico entre secret (segredo) e excrement (excremento).

Por fim, como mostra a etnologia, a separação e circulação desses dejetos do corpo dão sempre lugar a ritos de purificação. Eis que se torna possível compreender o papel desempenhado pelas instituições que estocam o material de engendramento: purificar (dessexualizar) este material, permitindo sua circulação. Papel muito importante, afirma a psicanalista, seja do ponto de vista psicanalítico, ritual fóbico e obsessivo, seja do ponto de vista etnológico, ritual de passagem e separação.

É provocativa e instigante a aproximação aqui sugerida entre os rituais fóbico e obsessivo, por um lado, e de passagem e separação, por outro. Com certeza, a abordagem dessa complexa aproximação exigiria ampla análise, tarefa que não é sem importância. Nos restringiremos, entretanto, aqui, apenas na indicação que se o ritual fóbico e obsessivo pode permitir, de algum modo, a separação entre o sujeito e o gozo mortífero - e é isso que Lacan, de fato, sustenta, quando aborda o sintoma pela ótica do sinthoma (LACAN, 1975-76/2005) - ele tampouco deixa de indicar que “o sintoma, em sua natureza, é gozo” (LACAN, 
1962-63/2005, p.140). Com efeito, esta paradoxal relação entre sintoma e gozo sublinhada por Lacan não deixa de estar indicada na equivalência revelada por Freud entre presente, criança, fezes e dinheiro: revela-se, aqui, de fato, a relação entre a preciosa moeda de troca mercantil — o tão útil dinheiro — e o excremento: dejeto inútil do corpo.

Os bancos e as instituições onde são estocadas as substâncias de gozo (esperma) e os dejetos inúteis do corpo (óvulos e embriões supranumerários) não apenas purificam esse material, permitindo que ele se torne objeto de trocas (as quais, é preciso dizer, não são nem puramente altruístas, nem claramente mercantis). Eles são, de fato, o lócus onde se produzem inúmeras e complexas reações de transmutação entre altruísmo, mercantilismo e erotismo; entre separação e alienação; entre utilidade e inutilidade; entre falta e excesso. Talvez não seja à toa que uma das principais dificuldades colocadas tanto para os bioeticistas quanto para os sujeitos enredados nas NTR seja a sinistra passagem que elas operam da representação de uma falta de filhos àquela, irrepresentável, de um excesso de embriões (CORREA, 2001).

A partir de suas leituras do ensaio de Mauss, Maurice Godelier e George Bataille nos fornecem elementos fundamentais para pensarmos isso que insiste como excesso impensável no cerne mesmo de uma lógica compreendida por vários autores (contra os quais se produz nossa reflexão) como fundamentada seja na mera doação objetiva de material biológico, seja na absoluta pureza do dom altruísta e desinteressado da vida, seja, enfim, na completa mercantilização perversa do homem. Além disso, eles nos proporcionam importantes ferramentas para refletirmos sobre o interesse e os limites da ética relacional proposta por Parseval.

É visando a abordagem deste excesso impensável, ignorado pelas compreensões aqui referidas, assim como uma reflexão sobre a ética relacional, que adentraremos a seguir as contribuições destes dois autores.

\section{GODELIER E BATAILLE: A TROCA DE MULHERES, 0 KULA E O POTLATCH}

Os esforços de Godelier, em sua leitura do Ensaio sobre a dádiva, serão voltados, em grande medida, para a distinção entre os objetos que circulam na dádiva, circulação cuja lógica é revelada por Mauss, e aqueles objetos que escapam a esta lógica, seja porque são postos, como mercadoria, à venda, seja porque, devido ao seu caráter sagrado, não são postos em circulação mas sim guardados para serem transmitidos. Segundo suas palavras:

"Eu me proponho a explorar as distinções que existem entre as coisas que se vende, aquelas que se dá e aquelas, enfim, que não se deve nem vender nem dar, mas guardar para transmitir. Evidentemente, o mesmo objeto pode sucessivamente ser comprado como uma mercadoria, circular como objeto de dom e de contradom, e 
enfim, ficar escondido em um tesouro de clã como uma coisa sagrada e, com isso, escapar por um certo tempo a qualquer forma de circulação, mercantil ou não.” (GODELIER, 2007, p.67)

Vamos nos deter nesse artigo apenas nos objetos que circulam na dádiva. Julgamos, entretanto, interessante explicitar a distinção formulada pelo autor não apenas porque ela proporciona um importante esclarecimento sobre a particularidade destes objetos, como também porque nos conduz a lançar uma questão: Estaria a circulação de material de engendramento operando, hoje, uma mistura entre estas três modalidades de objetos? E isso, seja pela mercantilização dos gametas e embriões, seja através da inclusão, no circuito do dom, dos embriões, objetos que são fortemente investidos imaginariamente, de um caráter sagrado. A respeito desta última possibilidade, vale lembrar que hoje não é mais Deus, mas nosso código genético que supostamente se encontra na razão de nosso destino.

Antes de buscar responder a esta questão, o que não nos parece, ao menos no momento, possível, analisemos agora os três exemplos de troca descritos por Godelier. Observaremos que cada um deles nos fornece importantes pistas para pensarmos diferentes elementos presentes na circulação de material de engendramento.

O primeiro exemplo provém de sua própria observação. Trata-se da troca de mulheres na sociedade Baruya. A seu respeito, o autor destaca que, diferentemente do que se poderia pensar, os contradons recíprocos não anulam as dívidas que cada clã engendrou com seu dom, o que indica que "dar de volta" (redonner) não é "devolver" (rendre). O que ocorre ao termo dos dons recíprocos é que cada clã "se encontra ao mesmo tempo superior ao outro como doador e inferior ao outro como donatário" (GODELIER, 2007, p.75). Assim, o que se produz não é a anulação mútua das dívidas, mas sim o seu equilíbrio. "Em virtude dessa lógica, observa o antropólogo, dons e contradons alimentam permanentemente obrigações, dívidas, que geram fluxos de serviços e de solidariedade recíprocas” (ibidem). Aqui está clara a diferença entre as trocas mercantis que, ao se concluírem, anulam todo e qualquer laço entre doador e donatário, e aquelas próprias aos dons, os quais, mesmo quando compensados com os contradons, deixam um lastro de laço entre aqueles que participaram das prestações: lastro de uma dupla e contraditória relação de poder, mesmo que sua tendência seja o equilíbrio.

Acima já indicamos a possibilidade de estarmos hoje diante de um importante e intrigante deslocamento: se Lévi-Strauss viu nos dons de mulheres e, mais particularmente na lógica que os rege, a base das normas de parentesco e de organização social, a atualidade nos "presenteia” com novas modalidades de dons - gametas e embriões — os quais podem, eventualmente, se encontrar na base de novas formas de laços de parentesco e de laços sociais. Posições contrárias 
a respeito da pertinência em se falar em efetivas transformações nesse campo dividem inúmeros pesquisadores de diversas áreas, tais como a antropologia, a sociologia, o direito, a psicanálise e a bioética, mas o que é inquestionável é que desta questão não podemos mais escapar.

Mais do que tomarmos um partido favorável ou contrário à concepção do surgimento de novos laços, julgamos pertinente formular, a partir deste primeiro exemplo abordado por Godelier, alguns questionamentos: não seria contraditória a lógica que rege majoritariamente as NTR, na medida em que busca ao mesmo tempo opor-se a toda forma de mercantilização das doações e recusar o estabelecimento de qualquer forma de laço entre doador e donatário?

Parseval critica, como vimos, esta lógica. A seu ver, ao impedir que o donatário possa restituir o dom, ela o coloca em situação de extrema fragilidade, devido à dívida eterna da qual se torna sujeito. É nesse sentido que ela propõe a ética relacional, que favoreceria a restituição do dom. Mas segundo Godelier, como vimos, a restituição não anula a dívida, apenas permite que se estabeleça uma dupla, e equilibrada, relação de poder entre doador e donatário. Cabe aqui, então, perguntar: de que forma(s) — seja socialmente instituída(s) seja singularmente inventada(s) — poderia o donatário restituir um dom de engendramento de modo a que se estabeleça um equilíbrio nas relações de poder? E como compreender este equilíbrio? Haveria aqui, de fato, a possibilidade de produzi-lo? Ou a lógica relacional propõe algo impossível? Eis algumas das questões que os comentários de Godelier a respeito das trocas de mulheres por ele observadas nos levaram a formular.

Deixaremos estas questões em aberto para abordarmos agora o segundo exemplo de troca comentado por Godelier. Trata-se do kula, prática observada por Malinovski entre os trobriandeses, e referida por Mauss como “o mais solene de um vasto sistema de prestações e de contraprestações” (1950/1974, p.83). No kula, um objeto precioso é posto em circulação por seu proprietário para receber outro objeto em seu lugar. O intrigante aqui é que este objeto precioso, ao ser posto em circulação, continua, mesmo depois de dado, a ser posse do doador. O seu donatário o possui apenas provisoriamente (o doador pode a qualquer momento pedir sua restituição) e não tem sobre ele direito de propriedade, mas unicamente de uso - uso exclusivo para fazer outros dons. Como observa Godelier, o kula evidencia o fato de que os objetos doados são alienados na circulação dos dons sem deixar de permanecer ao mesmo tempo propriedade inalienável de seu doador originário.

Aqui, as semelhanças entre os objetos kula e o material de engendramento, assim como as interrogações a que estas semelhanças nos conduzem, parecem insinuar-se de forma mais clara. Bens alienáveis, passíveis de serem colocados em circulação sob a forma de dons, mas que não deixam de permanecer pro- 
priedade inalienável de seu doador originário. Este fantasma ronda, de fato, todo o dispositivo da reprodução tecnológica. Não basta que se afirme que a filiação é sempre uma construção social e psíquica e jamais um mero fato genético: o fantasma insiste. E se não forem simplesmente, como sustentam vários autores, a hegemonia do discurso biologizante ou o império da genética que se encontram na base da persistência desse fantasma que insiste, mas sim o saber inconsciente - social e singular - de que, nas doações de material de engendramento, aquilo que é doado não se separa de seu doador?

Se levarmos a sério Mauss e Godelier, não podemos reduzir as fantasias relativas ao poder do(s) doador(es) — fantasias que colocam com grande frequência os donatários em situação de fragilidade para sustentar a integridade de suas maternidades e paternidades - unicamente à confusão entre genitores e mães/ pais. É preciso considerar que entre estes dois termos, um terceiro se coloca: o material de engendramento doado. E com isso uma maior complexidade se apresenta, exigindo novas abordagens, que não se reduzem àquela velha e simples oposição entre o genético dado, por um lado, e a cultura ou subjetividade produzida, por outro.

O terceiro exemplo abordado por Godelier, no qual iremos nos deter mais devido à sua importância para nossa reflexão, é o potlatch, prática presente em algumas tribos indígenas do Noroeste americano e que exprime o ápice do dom antagonista. O que é posto em circulação no potlatch, com o objetivo de conquistar ou conservar títulos, status ou poder, são doações ostentatórias - excessivas de riquezas durante festas ou competições, por parte de chefes de tribos com a finalidade de humilhar, desafiar, submeter um rival.

Como observa o antropólogo, no potlatch "não estamos mais na lógica dos dons e contradons não agonísticos, que culminam em uma repartição relativamente igual dos recursos necessários à reprodução dos grupos sociais” (GODELIER, 2007, p.77) Ao contrário, o verdadeiro potlatch é aquele que torna impossível a retribuição. Assim, essa prática social recebe sua melhor forma quando a dádiva adquire uma força em face da qual não é possível a retribuição por parte do adversário:

\footnotetext{
“No potlatch se dá alguma coisa para 'esmagar' o outro com este dom. Por isso se dá mais do (do que se pensa) que ele poderia restituir ou se restitui muito mais do que aquilo que ele deu. Como com os dons e contradons não agonísticos, o dom-potlatch endivida e obriga aquele que o recebe, mas o objetivo visado é explicitamente tornar muito difícil, se não impossível, o retorno de um dom equivalente: trata-se de colocar o outro em dívida de modo quase permanente, de fazer com que perca seu prestígio publicamente, de afirmar assim, pelo máximo tempo possível, a própria superioridade." (GODELIER, 1996/2001, p.88)
} 
Assim, mais do que a constituição de laços sociais marcados pelo equilíbrio, como é o caso do kula, os laços produzidos pelo potlatch são necessariamente marcados pelo desequilíbrio de poderes.

Mas as doações aqui não se dão exclusivamente por meio de presentes excessivos: podem também ocorrer destruições espetaculares da própria riqueza. Há exemplos de destruições suntuárias de escravos, cachorros, incêndios de aldeias e afundamento de canoas. Assim, é próprio também desta forma de dom o fato dela ser marcada, mais do que pelo princípio da posse, pelo princípio da perda. No potlatch, com efeito, o poder maior para um chefe é referido à sua capacidade de perder. O material deve ser dilapidado para que ocorram os ganhos do nível imaterial, ou ainda, a honra e a glória são uma aquisição paralela à perda material. Como esclarece o seguinte trecho: “a riqueza aparece como aquisição enquanto um poder é adquirido pelo homem rico, mas ela é inteiramente dirigida para a perda, no sentido em que esse poder é caracterizado como poder de perder. É somente pela perda que a glória e a honra lhe são vinculadas” (idem, p.36).

Podemos afirmar, então, que o objeto que circula no potlatch é da ordem de um excedente acumulado para sua dilapidação. Se seguirmos a reflexão de Caillé (1998), há nesta forma de dom a afirmação de um antiutilitarismo por excelência; o apontamento para a zona daquilo que nas sociedades humanas escapa aos registros da razão utilitária ou do serviço dos bens. No entanto, segundo o autor, o ineditismo da teoria de Marcel Mauss não está apenas em afirmar que a ordem social é irredutível à ordem econômica utilitária. Este postulado não chega a ser uma novidade, pois o encontramos na sociologia clássica em autores como Weber, Simmel e Tocqueville. O ineditismo do paradigma do dom seria o fato de ele propor um “antiutilitarismo positivo" (CAILLÉ, 1998), isto é, que aparece como fundamento de outra ordem social.

Em relação às leituras feitas acerca do potlatch, o fato de este ser regulado pelo princípio da perda levou o filósofo Georges Bataille a elaborar a noção de desperdício para pensar em um modo de economia que regeria tanto os indivíduos como os sistemas sociais. Bataille destacou o potlatch como uma ordem social que exige necessariamente a dilapidação dos bens.

A compreensão da dilapidação dos bens fora trabalhada por Bataille em um ensaio chamado “A noção de despesa”, de 1933, no qual afirmava haver nos grupos sociais, em permanente estado endêmico, uma energia excedente que necessita ser despendida. As ideias centrais deste trabalho foram reelaboradas bem mais tarde, em seu livro A parte maldita (1949).

Dessa maneira, Bataille (1933) propõe que a noção de gasto improdutivo indicaria um modo de atividade econômica que se opõe ao princípio da utilidade clássica. Se para a utilidade o importante é a aquisição e conservação dos bens, reprodução e conservação da vida, constata-se que há um domínio da 
sociedade humana que visa a perda e a dilapidação dos bens. Não parece ser possível para o domínio da utilidade conceber "que uma sociedade humana possa ter interesse em perdas consideráveis, em catástrofes que provoquem, de acordo com necessidades definidas, depressões tumultuosas, crises de angústia e, em última análise, um certo estado orgíaco” (BATAILLE, 1949/1975, p.28).

Existe, portanto, uma contradição entre as concepções sociais clássicas e as necessidades reais da sociedade, na qual subjaz a exigência do desperdício.

Assim, o princípio da perda reivindica que o consumo pode ser tanto para o uso da energia necessária para a conservação da vida e da espécie, como também para as despesas improdutivas, motor primeiro das instituições econômicas. Esse modo de desperdício aparece nas festas, no luxo, nas guerras, nos jogos, nos enterros, nos espetáculos e em várias outras atividades da vida social.

O filósofo francês salienta que a economia clássica não pôde supor que a troca tivesse como causa não a necessidade de adquirir, mas, ao contrário, a exigência de destruição e perda. As concepções econômicas desenvolvidas por Bataille são, portanto, uma espécie de inversão do pensamento econômico comum, pois a dimensão do excesso está necessariamente inclusa no sistema de trocas.

Se o kula coloca em cena a fundamental questão do caráter inalienável — no sentido seja imaginário, simbólico ou real — do material de engendramento, o potlatch nos remete justamente para a presença, nas novas tecnologias reprodutivas, daquilo que nela permanece como excesso e, mais precisamente, como excesso produzido para ser dilapidado. Referimo-nos àquilo que constitui o principal tema das discussões bioéticas atuais: os chamados embriões supranumerários. Com efeito, as novas formas de fabricação do humano — supostamente regidas pela gestão racional, razão instrumental ou lógica calculista — supõem, ao menos até hoje, a produção de um estranho resto, uma indesejável sobra ou um inconveniente excedente.

É fundamental, entretanto, observar, tal como fez Caillé a respeito do potlatch, que a produção desse excesso - que permanecerá congelado até que um destino (transferência, doação ou descarte) lhe seja dado — não é mero desvio ocasional da gestão, razão e lógica acima mencionadas. Ao contrário, ela se encontra em sua origem: é sua condição de possibilidade — sem produção de um número maior de embriões do que aqueles que serão transferidos para a mulher, há parcas chances de resultado do tratamento. As novas formas de fabricação do humano dependem, portanto, tanto da circulação do material de engendramento (em sua suposta gestão racional) quanto da produção de um excesso que, dado as dificuldades de sua representação e as dificuldades subjetivas de lhe conferir um destino, colocam em cena o desatino e a vulnerabilidade tanto das técnicas quanto dos sujeitos nelas envolvidos.

Cabe salientar que se no potlatch a voluntária dilapidação dos bens é uma forma do sujeito afirmar seu poder, o chamado descarte de embriões — ou, ao 
contrário a proibição de descarte desse excesso (que ocorre, por exemplo, do Brasil) — traz à cena, antes, a negação do poder, a sideração ou o desamparo dos sujeitos que têm de se haver com um resto diante do qual não sabem o que fazer, e nem tampouco como representar ou nomear.

Vale indicar algumas das questões, filosoficamente formuladas pelos bioeticistas ou imaginariamente colocadas por doadores e donatários, quanto ao estatuto do embrião excedente: seria ele coisa morta ou ser vivo?; simples material biológico ou filho à espera de pais que, pela transferência para um útero, o adotem? mera coisa descartável e comercializável ou pessoa em potencial cuja dignidade deve ser resguardada? A dupla impossibilidade — seja de fugir à formulação dessas questões, seja de lhes fornecer uma resposta — delimita os contornos do caráter traumático, ou mesmo catastrófico do universo dos embriões excedentes.

Essa diferença não anula, entretanto, o fato que nos interessa salientar: na base da suposta razão utilitarista que rege as novas formas de reprodução, encontra-se a necessária produção de um excesso marcado pela impossibilidade de representação e destinado à dilapidação. Produção e dispêndio de vida, reprodução e descarte enodam-se aqui de forma tal que somos obrigados a pensar que o motor primeiro das NTR pode não estar na viabilização da gestão racional da reprodução por indivíduos autônomos, mas, ao contrário, na produção excessiva de vida a ser descartada por sujeitos siderados.

Bataille intrigou-se com a estranha relação que no potlatch se estabelece entre a produção social, por um lado, de perdas consideráveis, angustiadas ou mesmo catastróficas e, por outro lado, certo estado orgíaco. Trazendo essa relação para o contexto das NTR, somos levados a buscar tornar manifesta o que compreendemos como uma latente e potente relação entre a razão utilitarista — que busca controlar, de forma calculista, a reprodução do homem e do social - e uma razão antiutilitarista que se encontra no motor de uma produção excessiva de potencialidade de vida destinada a uma orgiástica dilapidação.

Recebido em 9/3/2015. Aceito em 13/3/2015. 


\section{REFERÊNCIAS}

BATAILLE, G. (1933/1975) “A noção de despesa”, in A parte maldita. Rio de Janeiro: Imago.

. (1949/1975) A parte maldita. Rio de Janeiro: Imago.

CAILLÉ, A. (1998) Nem holismo nem individualismo metodológicos. Marcel Mauss e o paradigma da dádiva. Revista Brasileira de Ciências Sociais, v.13, n.38, São Paulo: Anpocs, p.5-38.

CORREAA, M. (2001) Novas tecnologias reprodutivas. Limites da biologia ou biologia sem limites? Rio de Janeiro: Eduerj.

DELAISI DE PARSEVAL, G.; VERDIER, P. (1994) Enfant de personne, Paris: Odile Jacob.

GODELIER, M. (1996) “Les logiques du social. Systématiques de parenté et représentations symboliques”, in Masculin/Féminin. Paris: Odile Jacob, p.253-275.

(1996/2001) O enigma do dom. Rio de Janeiro: Civilização Brasileira.

(2007) Au fondement des sociétés humaines Ce que nous apprend l'anthropologie. Paris: Albin Michel.

LACAN, J. (1962-63/2005) O seminário, Livro X: A angústia, Rio de Janeiro: Jorge Zahar.

. (1975-76/2005) O seminário, livro XXIII: O sinthoma. Rio de Janeiro: Jorge Zahar.

LÉVI-STRAUSS, C. (1924/1974). "Introdução à obra de Marcel Mauss", in: MAUSS, Marcel. Sociologia e antropologia. Rio de Janeiro: Edusp.

MAUSS, M. (1924/1974) "Ensaio sobre a dádiva. Forma e razão da troca nas sociedades arcaicas”, in Sociologia e antropologia. Rio de Janeiro: Edusp.

Simone Perelson

simoneperelson@,oi.com.br

Isabel Fortes

mariaisabelfortes@gmail.com 